University of Nebraska - Lincoln

DigitalCommons@University of Nebraska - Lincoln

To Improve the Academy

Professional and Organizational Development Network in Higher Education

1998

Becoming a Multicultural Faculty Developer: Reflections from the Field

Diana Kardia

Follow this and additional works at: https://digitalcommons.unl.edu/podimproveacad

Part of the Higher Education Administration Commons

Kardia, Diana, "Becoming a Multicultural Faculty Developer: Reflections from the Field" (1998). To Improve the Academy. 406.

https://digitalcommons.unl.edu/podimproveacad/406

This Article is brought to you for free and open access by the Professional and Organizational Development Network in Higher Education at DigitalCommons@University of Nebraska - Lincoln. It has been accepted for inclusion in To Improve the Academy by an authorized administrator of DigitalCommons@University of Nebraska - Lincoln. 
Kardia, D. (1998) Becoming a multicultural faculty developer: Reflections from the field. In M. Kaplan (Ed.), To Improve the Academy, Vol. 17 (pp. 15-34). Stillwater, OK: New Fonums Press and the Professional and Organizational Development Network in Higher Education. Key Words: change, diversity, faculty development, multicultural education, multicultural skills, personal development.

\section{Becoming a Multicultural Faculty Developer: Reflections from the Field ${ }^{1}$}

\section{Diana Kardia}

University of Michigan

There has been a significant amount of activity in the area of multicultural faculty development; yet, this is an area where our profession continues to require growth and attention. Many faculty development practitioners are in a unique position to work with multicultural issues but need additional knowledge, strategies, and skills to do this work well. By attending to the specific challenges and areas of expansion needed for faculty developers to work with diverse institutions, we can increase the effectiveness of our work while continuing to actualize the potential of our profession.

Multicultural education and faculty development are historical siblings: both have significant roots in the 1960s and 70s; both are based in humanistic and change-oriented efforts aimed at creating more inclusive and effective learning environments. The intersection of

\footnotetext{
I gratefully acknowledge the counsel and perspective of Shari Saunders and Connie Cook and the editing expertise of Rachel Stivenson during the development of these reflections.
} 
these two movements is evident in the faculty development literature. Past issues of To Improve the Academy (TIA) and other publications have addressed the role of faculty development programs in multicultural education (Marchesani \& Adams, 1992; Ouellett \& Sorcinelli, 1995; Schmitz, Paul, \& Greenberg, 1992; vom Saal, Jefferson, \& Morrison, 1992; Winter, 1991; Wunsch \& Chattergy, 1991) as well as topics such as promoting equity and cultural sensitivity in college and university classrooms (Collett, 1990; Hilsen \& Petersen-Perlman, 1994; Wadsworth, 1992), conducting discussions in diverse classrooms (Knoedler \& Shea, 1992), and curricular integration of cultural diversity concepts (Flannery \& Vanterpool, 1990). Work has also been done to identify the common goals of multicultural education and faculty development including promoting self-reflection among faculty (Bell, et al., 1997; Cooper \& Chattergy, 1993), increasing faculty knowledge and awareness of diverse students and diverse learning styles (Adams, Jones, \& Tatum, 1997; Anderson, 1997; Hardiman \& Jackson, 1992), increasing active learning and participation of all students (Adams, 1992; Hilsen \& Peterson-Perlman, 1994), and promoting critical thinking in the learning process (Sfeir-Younis, 1993). Furthermore, a number of faculty development programs are beginning to identify multicultural education as part of their deliberate agenda. A 1991 study by Border and Chism (1992) surveyed fiftythree faculty development centers on this topic. Of the twenty-three that responded, fifteen had existing multicultural programs and the remaining eight all had plans for implementing such a program in the future.

Yet, multicultural education and faculty development have not been integrated at the level one might expect, despite these historical and theoretical ties. A recent article in $T I A$ speaks to this disconnection:

For more than two decades, various faculty members and student groups have been engaged in developing institutional and curricular structures to promote a more multiculturally inclusive campus... During the same time period, the faculty led a curriculum revision that resulted in the requirement that all students take two social diversity courses within the campus-wide general education curriculum and institute diversity programs in the residence halls. Still, the needs of teaching 
assistants and faculty members for support and skills development in teaching these and other courses had never been directly or comprehensively addressed. Instructors had little opportunity to explore teaching practices that relate to diverse learning styles, to become better equipped to handle classroom dynamics that result from student diversity, and to incorporate teaching methods that address the needs and interests of our broadly diverse student populations. (Ouellett \& Sorcinelli, 1995)

Other articles in TIA have addressed related concerns. Examples include the strong emphasis on students' assumptions and challenges relating to cultural diversity without enough related attention to the faculty's assumptions and challenges (Cooper \& Chattergy, 1993); a historical emphasis within faculty development on supporting a masculine value system within higher education through a focus on skill development and expertise rather than on connection, community, and relationship in the classroom (van der Bogert, 1990); and a paucity of programs specifically designed to help faculty respond to bias in the classroom (Weinstein \& Obear, 1992). The lack of integration between multicultural education and faculty development is also noted by Schoem (1993) in his description of efforts to integrate diversity issues into a teaching assistant training program: "Training academics in multicultural teaching is most certainly not what anyone is typically credentialed or rewarded highly for doing" (p. 272).

What accounts for this inconsistent union between faculty development efforts and multicultural education? And what goals should we have for this union in the future? These questions prompt useful reflection about both the nature and scope of faculty development work.

It may be that many faculty developers assume that multicultural faculty development work is and should be done only in response to requests for this kind of service and, then, only by those individuals with expertise in this arena. This approach is consistent with the typical support role provided by faculty developers as evidenced in the following quote by Fink (1988):

I sometimes face the danger and temptation of telling clients more than they want to know. After visiting their classes, I may see a host of problems. But I have to select only one or two as the most important ones to start working on. (p. 12) 
In this context, multicultural concerns may often receive a lower priority in faculty development work because a) few faculty request attention to these specific concerns and/or b) other issues may present as needing more immediate attention. Furthermore, faculty development work often calls for a cautious and non-confrontive approach to discussions with faculty members in which the interests and assumptions of the faculty member strongly influence the possibilities and limitations of the discussion.

Occasionally I may see the need to change a person's agenda...This deviation from the general principle of identifying and adhering to the client's agenda can work. But it should be used judiciously and only in those cases where the consultant knows the client would be open to a different agenda. (Fink, p. 12)

While the majority of faculty may be committed to concerns regarding students' experiences in their classroom and providing multiple perspectives in their curriculum, these same faculty may treat direct discussion of multicultural issues with suspicion. Thus, the politicized nature of these issues may further limit multicultural faculty development efforts.

Fortunately, this is familiar territory to us. In order to engage in successful faculty development efforts of any kind, we as faculty development practitioners must be able to carefully attend to the opportunities and challenges present within our institution in order to take strategic, appropriate, and effective steps in promoting faculty, instructional, and organizational development. We must be able to introduce new concepts, perspectives, and pedagogical priorities in a non-threatening manner that is responsive to the realities, values, and needs of the specific faculty members with whom we work. Thus, faculty developers are uniquely skilled and situated to integrate diversity and academic excellence, as articulated by Anderson (1997):

The voice which, historically, has not been as resonant [with respect to the inclusion of diversity in the college classroom] but which will be called upon more in the future for advice and insight is that of the faculty development specialist...Faculty development specialists can assume the critical role of leading or, at least, participating in the discussion about an enhanced curriculum. They can promote a discourse which maintains a focus on academic rigor and faculty values. They can help 
to mollify the anxieties of faculty and administrators who fear the challenge to tradition, and who are too myopic to foresee the enormous benefit associated with connecting, in new ways, the curriculum to diversity. (pp. 46, 48)

Embedded in this rationale is the assumption that attention to race/ethnicity, gender, sexual orientation, disability, and other student characteristics is consistent with an improved learning environment for all students. The accuracy of this assumption is evidenced in multiple ways. For example, an instructor who provides more lead time with assignments in response to the needs of a student with a physical disability will be appreciated by all students, even though the majority of the students might have been able to find ways to compensate for the lack of lead time. Similarly, responding to the diversity in cultures and learning styles in the classroom can also benefit all students (Anderson, 1997). "The benefits of instructional flexibility...extend to the traditional student as well, because varied teaching is effective teaching in any event. It increases the likelihood of matching learning differences for all students, while providing regular practice and development [for faculty] in their less preferred modes" (Marchesani and Adams, 1992, p. 17). Furthermore, once defined, the very nature of multicultural issues requires of us a more proactive response: "For those of us committed to strengthening our academic communities, recognizing this fear and isolation, oppression and invisibility, discomfort and misunderstanding, demands that we both join the conversation and work to reduce barriers" (Ferren \& Geller, 1993, p. 99).

Given the motivation and possibilities for an increased commitment to multicultural faculty development efforts, this article addresses the challenges and implications for faculty developers who make such a commitment - the skills we need to develop, the information we need to pursue, the perspectives we might take, in order to do this work well. I write this as a faculty development practitioner who has come to this field recently after working for a number of years (through both teaching and research) within a multicultural education framework. I offer it as a contribution to an ongoing national dialogue about doing multicultural work in the field of faculty development. 


\section{Casting a Wider Net: Expanding What We Know and What We Do}

Explicit integration of the goals and questions of multicultural education into a faculty development framework requires casting a wider net to fully address the student experiences and the faculty practices that need attention. In particular, it requires that, as faculty developers, we may need to expand our knowledge base, our pedagogical strategies, our professional skills, and our reflection on ourselves as individuals working in multicultural institutions.

\section{Expanding Our Knowledge Base}

The first and most obvious implication of embedding multiculturalism into faculty development work is the need for an increased knowledge base. A faculty developer working with multicultural issues must be aware of the cultural issues that inform our understanding of students, faculty, classroom dynamics, and teaching and learning strategies (Adams, Jones, \& Tatum, 1997; Adams \& Marchesani, 1992). Additionally, more than cursory attention to this knowledge is required: "Partial, generalized knowledge of culturally diverse groups in the United States is not enough if effective change in the way that faculty approach the inclusive classroom is to be achieved. Liberal, well-intentioned strategies, if based on insufficient understanding, may have negative results" (Collett \& Serrano, 1992). This also means learning about issues relating to race/ethnicity, gender, sexual orientation, disability, class, religion, and other manifestations of diversity on campus. Such learning may be more than an intellectual challenge, as exemplified by Ferren and Geller (1993) in an article about sexual orientation and faculty development: "Are we, as faculty developers, ready for this commitment to the inclusion of the gay, lesbian, and bisexual community? Are we ready to deal with our lack of knowledge and our fears?...Questions about sexual orientation are not easy to ask, nor to answer" (p. 100). While recognizing this difficulty, they go on to point out the importance of faculty developers taking a proactive role with this issue: "To encourage conversation and provide leadership, a faculty developer must be prepared to publicly answer the...question, 'What does sexual orientation have to 
do with teaching and learning?'" (p. 102). By being prepared with the answer to this and related questions (regarding other social categories), faculty developers can educate faculty about relevant issues and promote pedagogical improvements that are well grounded in the specific needs of multicultural classrooms.

In order to answer such questions, basic knowledge of the various social categories is, in itself, not enough. It is important to extend this knowledge to include an awareness of the social dynamics and challenges typically encountered in interacting across our differences. This involves explicit attention to questions such as who is being alienated, isolated, or injured in our classrooms (Marchesani \& Adams, 1992). By asking these questions, it is possible to expose hidden norms and cultures in a classroom setting and identify the cultures, styles, and experiences that are being excluded. For example, attention to these questions may reveal an overly competitive classroom climate that inadvertently privileges the participation of some students while marginalizing students whose participation is influenced by more collaborative norms. These questions can also help identify false assumptions about students, such as the assumption that some students are underprepared, unmotivated, or unintelligent. While these adjectives can be applicable to particular students, such assumptions may also be applied to students who bring strong skills and intelligence to the classroom but for whom the existing pedagogical practices are not a good match (as a result of not teaching to the diversity of learning styles in the class). Such assumptions may also be fueled by social stereotypes and norms (Marchesani \& Adams, 1992; Tobias, 1990).

A third area of knowledge needed by the multicultural faculty developer is student, faculty, and identity development. This includes topics such as racial identity development (Hardiman \& Jackson, 1992) and the learning styles of diverse learners (Anderson \& Adams, 1992), as well as an understanding of socialization processes. Faculty developers can play a key role in articulating to faculty the rationale for heightening their awareness of student development issues as well as the impact of faculty identity on class dynamics. Faculty who seek to teach to a diverse student body may need to develop proactively their own self-awareness in order to examine such influences on their teaching as generational differences, stereotypes and misinformation, 
and the limits of their own perspectives as determined by their own cultural influences (Cooper \& Chattergy, 1993; Marchesani \& Adams, 1992). Cooper and Chattergy (1993) point out that faculty are also characterized by an "internal multiculturalism" resulting from the ways in which "the various roles they occupy reflect differing and sometimes conflicting cultural imperatives"(p. 86). Increasing awareness of these internal conflicts and complexities can increase faculty's understanding of their own experiences, the institution, and the conflicts and complexities experienced by their students.

An awareness of their own identity and background may also prepare faculty to recognize their missteps in the classroom-their own acts of bias or problematic assumptions - or increase their ability to respond to students who raise this type of concern (Weinstein \& Obear, 1992). Awareness of their own cultural identity and their authority role in the classroom is also key in responding to students' acts of bias or incivility in the classroom (Weinstein \& Obear, 1992). "The self-reflective teacher, it is argued, could respond with greater insight to situations such as a student unknowingly making a racist comment, some students feeling excluded from class discussion because of communication styles, or other students complaining that their lab partner, from a different racial background, is causing their grades to suffer" (Schoem, 1993, p. 274). As faculty developers, our tendency to reflect on our own experience with learning and teaching often provides the connection through which we work with instructors on their teaching. Facility at reflecting upon our own experiences with exclusion, inclusion, power, and difference in the classroom can provide a similar mechanism through which faculty may become better able to understand their own role and experience in the classroom.

A final type of knowledge that may be new to faculty developers is related to the need for incorporating institutional policies and regulations into pedagogical programming. Workshops on topics such as dealing with controversial issues in class discussions need to be informed by the institution's definition of and policies regarding free speech, hate speech, and discriminatory language. Teaching orientation sessions for new instructors may need to include information or training regarding sexual harassment issues (Schoem, 1993). As insti- 
tutions become more explicit about the boundaries relating to language and behavior, faculty developers may need to be more prepared to represent these policies rather than just filling the more familiar (and more comfortable) role of offering supportive suggestions and ideas to improve teaching.

\section{Expanding Our Pedagogical Strategies}

The identification of pedagogical strategies is a second arena where a wider net can be cast when explicit attention is given to multicultural education in faculty development. Such strategies may be suggested by cultural practices that differ from those that are dominant in the US. An example of this is the use of "rounds," a tradition adapted from the indigenous people of North America, which provides all students with a chance to share their perspective without interruption before the discussion is opened up for interaction and cross-fertilization of ideas. Cultures that are more collectivist than the US also suggest new ways of approaching group work, grading, and student inquiry (Anderson, 1997; Wadsworth, 1992).

New pedagogical models for collaborative and interdisciplinary learning are also emerging from fields such as women's studies and ethnic studies (Schmitz, 1992). These pedagogical models are characterized by their explicit attention to the participation of individuals from non-dominant social groups as well as the influence of their interdisciplinary approach to knowledge. Because of this emphasis, these classrooms provide keen insight about such issues as students' voice and positionality, the role of authority in the classroom, and working with multiple perspectives in the classroom (Maher \& Tetreault, 1992).

\section{Expanding Our Professional Skills}

Expansion of the professional skills we bring to faculty development work is the third area in need of attention for effective multicultural faculty development. Some aspects of this expansion have already been addressed: the ability to work with sensitive topics in a politicized climate and the ability to work with faculty on self-reflec- 
tive activities that explore aspects of their cultural and social identity that may be relevant to their teaching.

Working with faculty to create inclusive classrooms may also raise a new kind of anxiety among faculty: concerns about being labeled "pc" (politically correct), responding to student anger or other emotions in the classroom, feeling uninformed or uncertain about campus or social issues that impact their classes, fears of losing control of their class, or feeling strong emotions of their own in response to classroom dynamics (Bell, et al., 1997; Frederick, 1991; Weinstein \& Obear, 1992). These anxieties are fueled by campus and social conflicts regarding diversity, but they also reflect the reality that becoming a multicultural teacher can make teaching harder:

A faculty colleague now observes that her heightened sensitivity to the variety of cultures in the classroom makes the multiplicity of subtle messages incredibly distracting. She used to be able to move through the content, lecturing with enthusiasm, answering the questions of the outspoken, and finishing as the class time ended. Now she notes every frown, sigh, and seating placement while worrying about whether all her students are finding the classroom a "good" experience. (Ferren \& Geller, 1993, p. 107)

This reality is echoed by Adams (1992):

It is obvious that multiculturally responsive teaching calls for a substantial commitment by college teachers, for whom such an agenda may well appear daunting, time consuming, emotionally demanding, full of pitfalls and unpleasant surprises, potentially unrewarded by senior colleagues, difficult to imagine in lecture sections of several hundred students, and possibly inefficient in its use of the fifty-minute class session already crowded by discipline-based syllabus coverage. (p. 14)

In responding to this reality, Adams stresses the need for long-term commitment by faculty. This suggests that faculty developers also need to view this work as being a long-term commitment-one that may require new modes of support for faculty and new types of programming.

This concern also arises as a need for faculty developers to have an increased tolerance for ambiguity and unanswered questions. The existing learning and pedagogical research and practice has taught us very concrete ideas for responding to the common concerns of instruc- 
tors: how to do group work, how to increase critical thinking, how to interest and engage students in their own learning, how to get students to do the reading. As the coordinator of the graduate student instructor workshop series at the teaching center where I work, I continuously flip through the variety of "how to" questions in search of a useful and appealing set of offerings for instructors who need answers today to help them with the students they will be facing the next morning in class. Multicultural workshop content, however, often cannot be pinned down so easily. While there are many specific suggestions and ideas we can provide, the challenges raised through controversial course content, diverse classrooms, and instructors who bring their own emotional, intellectual, and social challenges to these issues are not easy to answer. Furthermore, the insights and guidance we do have to offer on these issues are often not well suited to the one-shot framework of a typical faculty development workshop (Schoem, 1993).

This set of challenges suggests new types of programming and outreach to faculty as well. For example, in our center, we are giving increasing attention to department-based services that address multicultural topics. These services are often multi-faceted, including (but not limited to) consultations, resource development, staff retreats, climate assessments, and curricular review. This approach provides a more appropriate response to the complex and nuanced multicultural issues being encountered by faculty in these settings. We are also exploring more long-term programming that supports and enhances the general teaching culture at the university. Through this context, we seek to promote the opportunity for dialogue and reflection among faculty that can address the many challenges associated with teaching on a diverse campus.

\section{Expanding Our Self-Reflection}

The final dimension in need of expansion by faculty developers working explicitly with multicultural education is the ability to examine oneself. As a faculty developer working on multicultural issues, I need to be able to reflect on a variety of issues including: 
- what I know from experience versus what I need to learn from the experiences of others;

- my own cultural biases and blindspots that may interfere with my interactions with faculty;

- how I might be perceived by faculty whose experiences are significantly different from my own.

These processes are not new to the faculty developer-we must address these issues just to cope with disciplinary differences between ourselves and the faculty with whom we work. However, they take on additional meaning and challenge when applied to increasing our awareness of our own identities, socialization, and cultural patterns. With my experience in teaching both math and psychology, I need a certain type of openness to work well with a faculty member struggling with the process of teaching composition. As a white woman, I need to be even more aware of the nature and limits of my own experience in order to talk effectively and respectfully with a Latina faculty member concerned about her issues of authority in her classroom. There are ways I can bring both my expertise and personal experience to bear on this conversation, but there are also likely to be significant differences in my experience as a teacher as compared to hers.

Reflecting on my own experiences with teaching can also help me identify faculty experiences in need of support. For example, I am currently in the midst of developing programming on my campus for lesbian, gay, and bisexual faculty and graduate student instructors regarding sexual orientation in the classroom. As a lesbian who was typically "out" in the classroom, I bring a variety of experiences to this programming. At the same time, I need to again remember the limits of my experience and seek other resources to inform this programming. Teaming up with my heterosexual colleagues has been particularly useful in reminding me of the assumptions and predispositions I bring to this work. Reading about the experiences of others is also an important dimension of the self-reflective process, helping me to better understand my own experience and gain insight into the experiences of others. For example, two books of particular relevance on this topic are Tilting the Tower: Lesbians Teaching Queer Subjects, 
edited by Linda Garber, and Teaching What You're Not: Identity Politics in Higher Education, edited by Katherine J. Mayberry.

Discussion with colleagues of various identities can also inform the other aspects of multicultural faculty development I have identified here. From an African-American woman colleague I learn about the concerns of women faculty of color expressed in a focus group that was able to create enough safety through its homogeneity for these concerns to surface. From a white-male colleague I learn about his conversation with a white-male faculty member regarding his struggles with authority -struggles that I normally associate with women faculty and faculty of color. And from a colleague who describes herself as a "quiet activist," committed to multicultural education but struggling with the language and forms that it sometimes takes, I gain insight into ways to approach faculty who are open to change but shy away from the politicized nature of the debates. The significance of such discussions is determined, in part, by paying attention to the differences between what I know through the filter of my own experience and what I can learn from others whose identities create different filters than my own.

\section{Becoming Multicultural Faculty Developers: A Call to Action}

"Multicultural classrooms are made, not born" (Schmitz, Paul, \& Greenberg, 1992, p. 75). Likewise, we must promote new knowledge, strategies, skills, and awareness in ourselves and our colleagues in order to fully actualize multicultural faculty development. We must work with each other to deepen our understanding of the need for and meaning of this work while also actively developing our capacity to carry it out. The stretches and changes required of us to do effective multicultural faculty development work do not just happen of their own accord.

We have at our disposal very effective avenues for doing this. As evidenced by the references in this paper, there are a number of people in our midst with expertise in this area-faculty development practitioners who have been working with multicultural classroom practices and curricular development for years who can serve as resources and 
models for our individual professional development. As already noted, there are also a growing number of institutions that are committed to taking leadership in this arena and can inform us regarding the institutional challenges involved in the development of multicultural programming. Beyond this expertise, we have the wide array of experiences and perspectives that are present in this profession-faculty developers from a diversity of professional and social identities who bring insights from their own experiences regarding learning, teaching, and working with faculty. This includes those of us who have given little explicit attention to multicultural work as well as those of us with more experience. It even includes faculty developers who, at first flush, may balk at the phrase "multicultural faculty development." Developing alliances within our profession across our identities, types of expertise, political leanings, and change strategies is as important to the work of creating inclusive classrooms for students and faculty as learning more information and skills. It is only by realizing and working with our own diversity that we can develop competence in attending to student diversity and working effectively with a diverse faculty.

In order to bring such alliances to fruition, we need to work together both locally and nationally. As faculty developers, we have a professional organization characterized by a commitment to collaboration that is unique in my experience in academia. Through the strength of this community, we have considerable resources for working with the challenges associated with multicultural faculty development both as individuals and as a profession. We may need to ask hard questions and share difficult truths with each other. We may need to promote our own critical thinking and active learning in much the same way our work is designed to help students who are challenged by new perspectives and diverse opinions. To accomplish this, we need to seek out colleagues within and across our institutions who think differently than ourselves or who have different life experiences. Through an exploration of the diversity and differences within our profession, we can expand our understanding of the needs and tensions of faculty and students and gain insight into new strategies for our faculty development programs. 
We need to actively create opportunities for discussion and participate in conversations we would have previously avoided. This means instigating collaborative and intentional dialogue that helps us clarify and understand our own experience while broadening our understanding of the perspectives, strategies, and experiences of others. Following are three simple activities that effectively promote such dialogue:

1) Articulate for yourself a working definition of multicultural faculty development. Then ask other colleagues to share their definitions with you. In this exchange, focus on trying to understand the similarities and differences in your definitions rather than on trying to reach consensus or convince the other person of your perspective.

2) Make some time to talk with other faculty development practitioners with whom you share a similar identity about the challenges and motivations they and you experience in doing this work. For example, it has been very helpful for me to talk with other white people who address multicultural issues in their work. Such exchanges have helped me to understand and normalize my own experience while also offering me new strategies for addressing the challenges I experience in this role.

3) Ask someone with whom you don't share a particular identity to tell you about their challenges and motivations in doing faculty development work (e.g., conversations I have had with my African-American or male colleagues). The emphasis here should be on listening, assuming that you're asking this question because there are significant aspects of the answer that you don't know from your own experience.

Through these discussions and ongoing reading and skill development in this area, we can promote both our individual and our collective ability to respond to the diversity on our campuses. Faculty development as it already exists has important perspectives and resources to bring to the efforts of our diverse institutions to be inclusive, effective learning environments for all. By rising to the challenges of multicul- 
tural faculty development, by actively working together as a diverse community, our institutions, our profession, and our individual lives may be greatly enriched.

\section{References}

Adams, M. (1992). Cultural inclusion in the american college classroom. In L. L. B. Border \& N. V. N. Chism (Eds.), Teaching for diversity. New Directions for Teaching and Learning, No. 49. San Francisco: Jossey-Bass.

Adams, M., Jones, J., \& Tatum, B. D. (1997). Knowing our students. In M. Adams, L. A. Bell, \& P. Griffin (Eds.), Teaching for diversity and social justice: A sourcebook. New York: Routledge.

Adams, M., \& Marchesani, L. S. (1992). Curricular innovations: Social diversity as course content. In M. Adams (Ed.), Promoting diversity in college classrooms: Innovative responses for the curriculum, faculty, and institutions. New Directions for Teaching and Learning, No. 52. San Francisco: Jossey-Bass.

Anderson, J. A. (1997). Faculty development and the inclusion of diversity in the college classroom: Pedagogical and curricular transformation. To Improve the Academy, 16, 41-52.

Anderson, J. A., \& Adams, M. (1992). Acknowledging the learning styles of diverse student populations: Implications for instructional design. In L. L. B. Border \& N. V. N. Chism (Eds.), Teaching for Diversity. New Directions for Teaching and Learning, No. 49. San Francisco: Jossey-Bass.

Bell, L. A., Washington, S., Weinstein, G., \& Love, B. (1997). Knowing ourselves as instructors. In M. Adams, L. A. Bell, \& P. Griffin (Eds.), Teaching for diversity and social justice: $A$ sourcebook. New York: Routledge.

Border, L. L. B., \& Chism, N. V. N. (1992). The future is now: A call for action and list of resources. In L. L. B. Border \& N. V. N. Chism (Eds.), Teaching for diversity. New Directions for Teaching and Learning, No. 49. San Francisco: Jossey-Bass.

Collett, J. (1990). Reaching African-American students in the classroom. To Improve the Academy, 9, 177-188.

Collett, J., \& Serrano, B. (1992). Stirring it up: The inclusive classroom. In L. L. B. Border \& N. V. N. Chism (Eds.), Teaching for diversity. New Directions for Teaching and Learning, No. 49. San Francisco: Jossey-Bass.

Cooper, J. E., \& Chattergy, V. (1993). Developing faculty multicultural awareness: An examination of life roles and their cultural components. To Improve the Academy, 12 , 81-95.

Curtis, M. S., \& Herrington, A. J. (1992). Diversity in required writing courses. In M. Adams (Ed.), Promoting diversity in college classrooms: Innovative responses for the curriculum, faculty, and institutions. New Directions for Teaching and Learning, No. 52. San Francisco: Jossey-Bass.

Diamond, R. M. (1988). Faculty development, instructional development, and organizational development: Options and choices. In E. C. Wadsworth (Ed.), A handbook for 
new practitioners. Stillwater, OK: New Forums Press and the Professional \& Organizational Development Network in Higher Education.

Ferren, A. S., \& Geller, W. W. (1993). Faculty development's role in promoting an inclusive community: Addressing sexual orientation. To Improve the Academy, 12, 97-108.

Fink, L. D. (1988). County agents and instructional consultants: Tips on establishing a successful consulting program. In K. G. Lewis (Ed.), Face to face: A sourcebook of individual consultation techniques for faculty/instructional developers. Stillwater, OK: New Forums Press.

Flannery, B., \& Vanterpool, M. (1990). A model for infusing cultural diversity concepts across the curriculum. To Improve the Academy, 9, 159-175.

Frederick, P. J. (1991). The Medicine Wheel: Emotions and connections in the classroom. To Improve the Academy, 10, 197-214.

Garber, Linda. (Ed.). (1994). Tilting the tower. New York: Routledge.

Hardiman, R., \& Jackson, B.W. (1992). Racial identity development: Understanding racial dynamics in college classrooms and on campus. In M. Adams (Ed.), Promoting diversity in college classrooms: Innovative responses for the curriculum, faculty, and institutions. New Directions for Teaching and Learning, No. 52. San Francisco: Jossey-Bass.

Hilsen, L., \& Petersen-Perlman, D. (1994). Leveling the playing field. To Improve the Academy, 13, 221-233.

Hunt, J. A., Bell, L. A., Wei, W., \& Ingle, G. (1992). Monoculturalism to multiculturalism: Lessons from three public universities. In M. Adams (Ed.), Promoting diversity in college classrooms: Innovative responses for the curriculum, faculty, and institutions. New Directions for Teaching and Learning, No. 52. San Francisco: Jossey-Bass.

Knoedler, A. S., \& Shea, M. A. (1992). Conducting discussions in the diverse classroom. To Improve the Academy, 11, 123-135.

Knowles, T., Medearis, C., \& Snell, A. (1994). Putting empowerment to work in the classroom. To Improve the Academy, 13, 203-211.

Maher, F., \& Tetreault, M. K. T. (1992). Inside feminist classrooms: An ethnographic approach. In L. L. B. Border \& N. V. N. Chism (Eds.), Teaching for diversity. New Directions for Teaching and Learning, No. 49. San Francisco: Jossey-Bass.

Marchesani, L. S., \& Adams, M. (1992). Dynamics of diversity in the teaching-learning process: A faculty development model for analysis and action. In M. Adams (Ed.), Promoting diversity in college classrooms: Innovative responses for the curriculum, faculty, and institutions. New Directions for Teaching and Learning, No. 52. San Francisco: Jossey-Bass.

Mayberry, K. J. (Ed.). (1996). Teaching what you're not: Identity politics in higher education. New York: New York University Press.

Mintz, J. (1994). Challenging values: Conflict, contradiction, and pedagogy. To Improve the Academy, 13, 177-190.

Ouellett, M. L., \& Sorcinelli, M. D. (1995). Teaching and learning in the diverse classroom: A faculty and TA partnership program. To Improve the Academy, 14, 205-217. 
Schmitz, B. (1992). Cultural pluralism and core curricula. In M. Adams (Ed.), Promoting diversity in college classrooms: Innovative responses for the curriculum, faculty, and institutions. New Directions for Teaching and Learning, No. 52. San Francisco: Jossey-Bass.

Schmitz, B., Paul, S. P., \& Greenberg, J. D. (1992). Creating multicultural classrooms: An experience-derived faculty development program. In L. L. B. Border \& N. V. N. Chism (Eds.), Teaching for diversity. New Directions for Teaching and Learning, No. 49. San Francisco: Jossey-Bass.

Schoem, D. (1993). Constructing a teaching assistant training program with a multicultural emphasis. In D. Schoem, L. Frankel, X. Zúñiga, \& E. Lewis (Eds.), Multicultural teaching in the university. Westport, CT: Praeger.

Sfeir-Younis, L. S. (1993). Reflections on the teaching of multicultural courses. In D. Schoem, L. Frankel, X. Zúñiga, \& E. Lewis (Eds.), Multicultural teaching in the university. Westport, CT: Praeger.

Tobias, S. (1990). They're not dumb, they're different: Stalking the second tier. Tucson, AZ: Research Corporation.

van der Bogert, V., Brinko, K. T., Atkins, S. S., \& Arnold, E. L. (1990). Transformational faculty development: Integrating the feminine and the masculine. To Improve the Academy, 9, 89-98.

vom Saal, D. R., Jefferson, D. J., \& Morrison, M. K. C. (1992). Improving the climate: Eight universities meet the challenges of diversity. In L. L. B. Border \& N. V. N. Chism (Eds.), Teaching for diversity. New Directions for Teaching and Learning, No. 49. San Francisco: Jossey-Bass.

Wadsworth, E. C. (1992). Inclusive teaching: A workshop on cultural diversity. To Improve the Academy, 11, 233-240.

Weinstein, G., \& Obear, K. (1992). Bias issues in the classroom: Encounters with the teaching self. In M. Adams (Ed.), Promoting diversity in college classrooms: Innovative responses for the curriculum, faculty, and institutions. New Directions for Teaching and Learning, No. 52. San Francisco: Jossey-Bass.

Winter, D. D. N. (1991). The feminization of academia. To Improve the Academy, 10, 115-121.

Wunsch, M. A., \& Chattergy, V. (1991). Managing diversity through faculty development. To Improve the Academy, 10, 141-150.

\section{Contact:}

Diana Kardia

Center for Research on Learning and Teaching

3300 School of Education Building

University of Michigan

Ann Arbor MI 48109-1259

(734) 647-6797

(734) 647-3600 FAX

dbd@umich.edu 
Diana Kardia is an Assistant Research Scientist and Instructional Consultant at the Center for Research on Learning and Teaching at the University of Michigan where she recently coordinated a national institute titled "Building Multiculturalism into Faculty Development." She has taught in Women's Studies and worked on curricular and pedagogical design in the Program in Intergroup Relations, Conflict, and Community at the University of Michigan. Her research interests include the impact of social identity on the teaching experiences of faculty (including student ratings) and the role of higher education in promoting sustainable diverse communities. She holds a Master's degree in Statistics and a PhD in Education, both from the University of Michigan. 